\title{
EVALUATION OF THE SPUR GEAR CONDITION USING EXTENDED FREQUENCY RANGE
}

\section{OCENA STANU PRZEKŁADNI ZĘBATEJ Z WYKORZYSTANIEM ROZSZERZONEGO ZAKRESU CZĘSTOTLIWOŚCI}

\begin{abstract}
The paper focuses on working out an algorithm for spur gear condition monitoring, based on the results of numerical simulation. The nonlinear mathematical model has been used for investigation of the dynamic parameters of the cylindrical spur gear with defective teeth. Backlash between gear teeth, backlash in bearings, time-varying mesh stiffness, and variations of the centre distance have been evaluated in the model. Diagnostic parameters suitable for determining the condition of the gears under investigation have been established. Frequency intervals mostly affected by changes in diagnostic parameters under damage have been found. An algorithm for diagnostics based on mathematical modelling, vibro-acoustic, and acoustic emission methods, and wavelet transform has been worked out.
\end{abstract}

Keywords: mathematical model; spur gear; acoustic emission; vibro-acoustic signal, wavelet transform, condition monitoring.

\begin{abstract}
Celem artykulu było opracowanie algorytmu monitorowania stanu przekładni zębatej w oparciu o wyniki symulacji numerycznej. Przedstawiono nieliniowy model matematyczny, który wykorzystano do badania parametrów dynamicznych przekładni zębatej walcowej z uszkodzonymi zębami. Za pomoca przedstawionego modelu oceniano luz pomiędzy zębami przektadni, luz w tożyskach, zmienna w czasie sztywność zazębienia oraz zmiany odległości osi. Ustalono parametry diagnostyczne odpowiednie dla określenia stanu technicznego badanych przektadni. Znaleziono przedzialy częstotliwości odpowiadające zmianom parametrów diagnostycznych wynikającymi z uszkodzenia. Opracowano algorytm diagnostyczny oparty na modelowaniu matematycznym, metodach emisji wibroakustycznej i emisji akustycznej oraz transformacie falkowej.
\end{abstract}

Stowa kluczowe: model matematyczny; przektadnia zębata; emisja akustyczna; sygnat wibroakustyczny, transformata falkowa, monitorowanie stanu.

\section{Introduction}

Improving equipment performance and increasing productivity are the major tasks for the operation of modern multi-purpose technological equipment. Spur gears are widely used in such equipment and gear damage may lead the whole system to failure, so condition monitoring is a commonly used way to improve reliability of equipment usage. Experimental research is the method most frequently used for the investigation of dynamic parameters of equipment. However, an experimental way cannot be the only technique for investigating off all possible combinations of operating parameters such as speeds and loads due to high costs and time spent for determining the causes. Mathematical modelling of a physical system employing numerical methods has become an effective alternative.

Spur gear mathematical models can be divided into analytical and numerical. Review of analytical models, where linear systems have been investigated, are presented in Ozguven and Houser [23]. Nowadays, usage of these models is limited, they are often used for calculations of the eigenvalues, also they can be used in systems where main research objects are not spur gears. One of the first nonlinear model was presented by Utagawa [32]. Author found out dynamic loads in the gear, by using time-variant stiffness. All data was compared with experimental investigation. Kahraman and Singh [9] investigated gear dynamics, when there is a backlash between gear teeth. Maliha et al. [18] investigated multibody system: gear, shafts, bearings, also backlash was included, others similar models were reviewed in [35]. Kiekbusch and Howard [11] presented equations for rotational gear mesh stiffness calculation in their investigation. Saxena et al. [27] used modified gear mesh stiffness model, which was based on potential energy method proposed by Yang and Lin [37]. The energy stored in meshing gear system was assumed to include four components: Hertzian energy, bending energy, axial compressive energy and shear energy. Multi-level gear models are presented in [2, 4, 35]. Cheon [2] has used Fourier series for mesh stiffness evaluation, backlash between gear teeth was taken into account and damping was included. Fakhfakh et al. [4] stiffness evaluated using time-variant function. Vaishya and Singh [33] proposed model where sliding friction in mesh was included. He et al. [7] compared five different friction models, authors investigated friction influence on gear dynamics. Amabili and Rivola [1] included mesh damping in their work. Kuang and Lin [12], Wojnarowski and Onishchenko [36] investigated gear teeth wear problem. Walha et al. [34] took bearing deformations and backlashes into account, meshing stiffness was proposed as a function. Frolov and Kosarev [5] investigated which parameters have most significant effect to gear dynamics. It was found that main parameters in gear dynamics are mesh stiffness, pitch errors, teeth surface errors. Jia and Howard [8], Fakher et al. [3] investigated pitting problem. Litak and Friswell [15] investigated teeth breakage, pitch errors. Zouari et al. [40] investigated teeth crack influence on mesh stiffness, authors changed crack level, crack direction, FEM was used for modelling. 
Mohammeda et al. [22] investigated tree different types of teeth cracks. First, crack is over all teeth and has constant value on every teeth width, second, crack depth is crack depth is distributed according to a parabolic function; third, crack is growing in all directions. As diagnostic parameters RMS and Excess were used, mesh stiffness was calculated using potential energy. Ma et al. [17] investigated a phenomenon of cracked teeth when the incoming tooth pair enters contact earlier than the theoretical start of contact, and the outgoing tooth pair leaves contact later than the theoretical end of contact. It was found that for simulated signals, sideband frequencies, statistical features and instantaneous energy can all reflect the fault features of the cracked gear.

Various methods, including the measurement of the vibro-acoustic signal (VS), oil debris method, sound measurement, acoustic emission (AE) and temperature measurement could be used for experimental identification of gear condition. VS and AE methods enable to identify variations in the condition and the type of a defect. The VS is a well-known method applied for testing the rotor system and widely described by Taylor and Kirkland [31]. This method has been extensively employed in the diagnostics of the rotor system. AE was originally developed for non-destructive testing of static structures; however, over the years, its application has been extended to health monitoring of rotating machines and bearings [20].

All measured data processing methods could be divided into three main domains [30]: time domain, frequency domain and timefrequency domain. Diagnostic parameters used in time domain are presented in Fig. 1, more information about these parameters can be found in $[6,10,14,16,19,21,24,25,26,38,39]$. Some of them can be also used in frequency and in time-frequency domains. Time synchronous averaging can be applied and filtering can be used, if signal has a lot of noise. Difference and residual signals are needed for some diagnostic parameters used in gear diagnostics [35].

In frequency domain, we can establish the type of the defect. Very powerful tool is signal analysis in time-frequency domain, it enables investigation of a signal not only according to frequencies, but on the time scale as well. It could be useful when a mechanism works at non-stationary modes. Methods generally used to process a signal in time-frequency scales are Short Time Fourier Transform (STFT), Wigner-Ville distribution, Choi-Williams distribution and Wavelet transform. Wavelet is not a direct time-frequency representation, but time-scale. If compared to STFT, Wavelet uses narrow time windows at high frequencies and wide time windows at low frequencies, using Wavelet transform computing time is decreasing. Skrickij et al. [28] showed that using wavelet transform and an extended frequency range, AE and VS signal monitoring of the gear unit is much more sensitive, and the occurrence of teeth faults and their growth can be recognized at an earlier stage.

The conducted analysis of mathematical models for spur gears has demonstrated that nonlinear dynamic systems must be examined in order to make the models for investigation of the dynamic parameters of defective gears. Also, the models of the gears must have the assessed backlashes in the bearings, and between gears. Mesh stiffness should be simulated as a time function and depend on the number of the pairs of gear teeth involved in the mesh as well as on the place of contact. Researchers do not focus on the defective top-part of the gear teeth, they mostly focus on teeth crack and pitting problem. The defect in the top-part of teeth appears in gearboxes when gears are moving in respect to each other during gear shifting.

In this paper diagnostic parameters suitable for determining the condition of the gears under investigation are established, frequency intervals with the most significant increase in the diagnostic parameter values are determined. Also it is found that diagnostic parameters are most sensitive to the occurrence and expansion of the defect when using the proposed mathematical model.

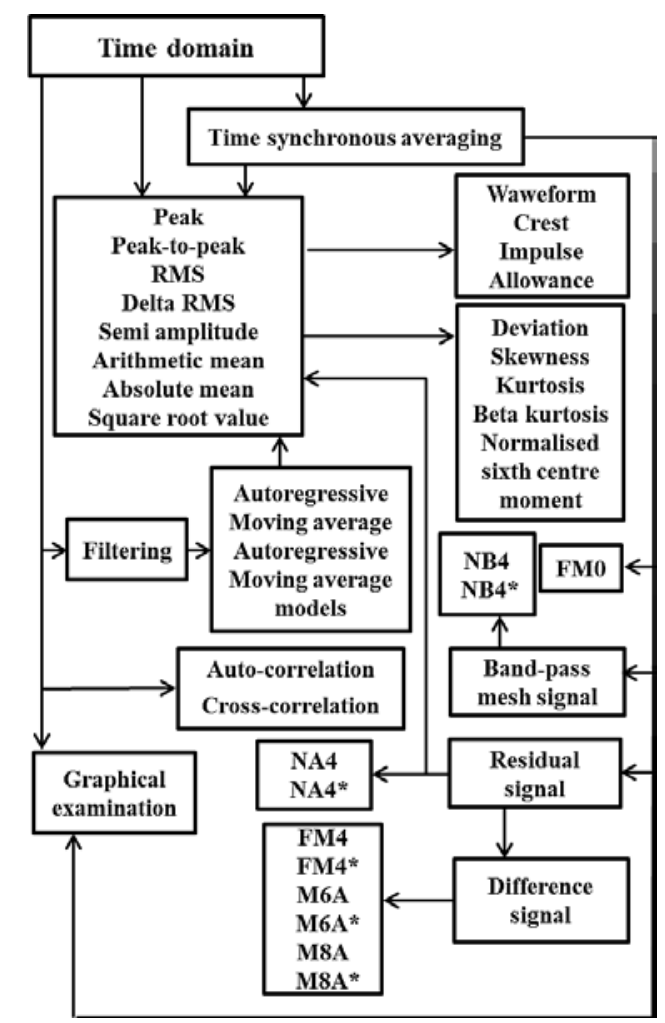

Fig. 1. Data processing methods

\section{Mathematical model for defective spur gear}

To investigate spur gear defect influence on its dynamical characteristics, nonlinear mathematical model was used. Gear is modelled as $2 \mathrm{D}$ system, only rotation around $\mathrm{x}$ axis and displacements in $\mathrm{y}, \mathrm{z}$ directions (Fig. 2) are taken into account; lubrication has not been included in the model; gear teeth deformations are taken into account; Kuang and Yang method [13] has been applied for time-variant mesh stiffness evaluation; shafts rotation deformations have been taken into account, bending and contact deformations have not been included; contact deformations in bearings have been estimated; backlash in bearings between rotation elements and inner and outer races has been estimated; backlash between gear teeth has been estimated; centre distance error has been evaluated; variations in centre distance due to gear work has been evaluated.

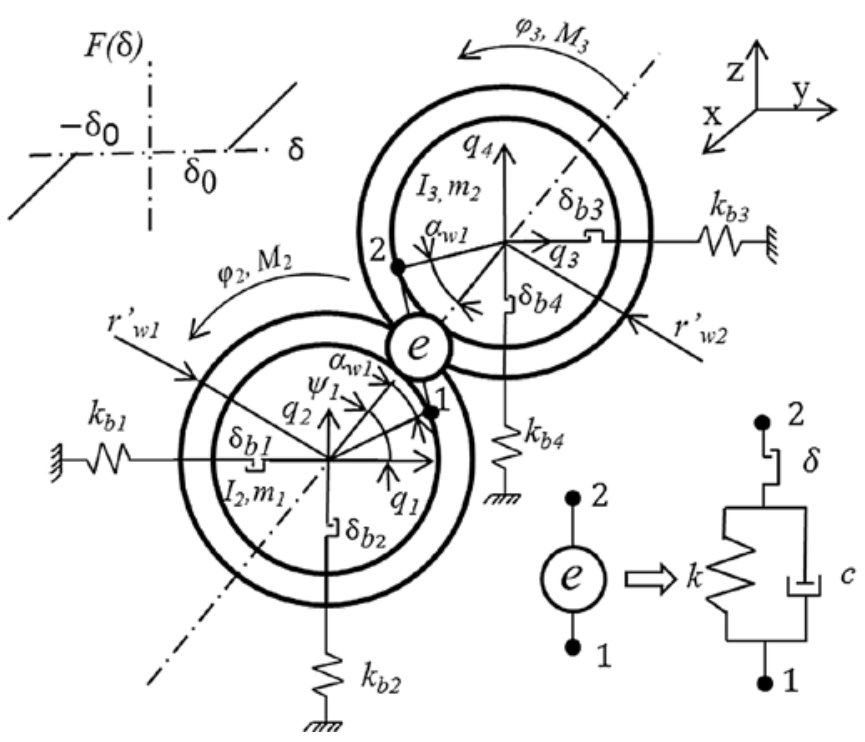

Fig. 2. Dynamic model of gear with backlash 
Errors may occur in the process of manufacturing, and number of faults is growing during gear operation, backlashes are getting wider and the flexibility of units is rising, centre distance is changing. The centres of gears are moving because rotation torques are applied. As for the operating mode of the mechanism, bearing flexibility is growing thus causing further changes in centre distance. Thus, a mathematical model of the gear train where variations in centre distance are evaluated was presented in [29].

Dynamic model of spur gear is presented in Fig. 2. The displacements of points 1 and 2 along a straight line, which is a tangent line to the circles of both gears (Fig. 2), are calculated as follows:

$$
\begin{gathered}
u_{1}=r_{w 1}^{\prime} \cdot \varphi_{2}-q_{1} \cdot \sin \left(\psi_{1}-\alpha_{w 1}\right)+q_{2} \cdot \cos \left(\psi_{1}-\alpha_{w 1}\right) \\
u_{2}=-r_{w 2}^{\prime} \cdot \varphi_{3}-q_{3} \cdot \sin \left(\psi_{1}-\alpha_{w 1}\right)+q_{4} \cdot \cos \left(\psi_{1}-\alpha_{w 1}\right) \\
\delta=u_{2}-u_{1}
\end{gathered}
$$

where $r_{w 1}^{\prime}$ is radii of the pitch circles; $\varphi_{2}, \varphi_{3}$ are rotation angles; $\psi_{1}$ is orientation angle; $\alpha_{w 1}$ is pressure angle; $q_{i}$ is displacement of gear, for $i=1,2,3,4$; parameters $\psi_{1}, \alpha_{w 1}, r_{w i}^{\prime}$ in this case are not constants, evaluation of these parameters are presented in [29]. The velocities of points 1 and 2 are calculated as follows:

$$
\begin{gathered}
\dot{u}_{1}=r_{w 1}^{\prime} \cdot \dot{\varphi}_{2}-\dot{q}_{1} \cdot \sin \left(\psi_{1}-\alpha_{w 1}\right)+\dot{q}_{2} \cdot \cos \left(\psi_{1}-\alpha_{w 1}\right) \\
\dot{u}_{2}=-r_{w 2}^{\prime} \cdot \dot{\varphi}_{3}-\dot{q}_{3} \cdot \sin \left(\psi_{1}-\alpha_{w 1}\right)+\dot{q}_{4} \cdot \cos \left(\psi_{1}-\alpha_{w 1}\right) \\
\dot{\delta}=\dot{u}_{2}-\dot{u}_{1}
\end{gathered}
$$

where $\dot{\varphi}_{i}=\frac{d \varphi_{i}}{d t}$ is angular velocity, for $i=1,2,3,4 ; \dot{q}_{i}=\frac{d q_{i}}{d t}$ is linear velocity. The influence of the backlash is showed in Fig. 2, parameter $\delta$ is a backlash. The force acting on mesh is obtained from the expression:

$$
F=-\mathrm{k} \tilde{\delta}-\mathrm{c} \cdot \dot{\delta}
$$

where $c$ is damping coefficient (Fig. 2); $k$ is mesh stiffness determined by the method offered by Kuang and Yang [13], where $\tilde{\delta}$ denotes the excess of displacement in view of the backlash of gears:

$$
\tilde{\delta}=\left\{\begin{array}{l}
\delta-\delta_{0}, \text { when } \delta>\delta_{0} \\
0, \text { when }-\delta_{0} \leq \delta \leq \delta_{0} \\
\delta+\delta_{0}, \text { when } \delta<-\delta_{0}
\end{array}\right.
$$

Stiffness of one tooth is evaluated using formulas:

$$
K_{i}(r)=\left(A_{0}+A_{1} X_{i}\right)+\left(A_{2}+A_{3} X_{i}\right) \frac{r-r_{w i}^{\prime}}{\left(1+X_{i}\right) m}
$$

where:

$$
\begin{gathered}
A_{0}=3.867+1.612 \cdot z_{i}-0.02916 \cdot z_{i}^{2}+0.0001553 \cdot z_{i}^{3} \\
A_{1}=17.060+0.7289 \cdot z_{i}-0.01728 \cdot z_{i}^{2}+0.0000999 \cdot z_{i}^{3}
\end{gathered}
$$

$$
\begin{aligned}
& A_{2}=2.637-1.222 \cdot z_{i}-0.02217 \cdot z_{i}^{2}+0.0001179 \cdot z_{i}^{3} \\
& A_{3}=-6.330-1.033 \cdot z_{i}+0.02068 \cdot z_{i}^{2}-0.0001130 \cdot z_{i}^{3}
\end{aligned}
$$

where $r$ is gear radii where load is applied; $X_{i}$ is a parameter in this mathematical model, it is assumed, that $X_{i}=0 ; m$ is gear module; $z_{i}$ is number of teeth in gear.

One tooth stiffness:

$$
k_{i}=K_{i}(r) \cdot b \cdot 10^{9}
$$

where $b$ is tooth width, if two teeth are in contact, mesh stiffness can be calculated:

$$
k=\frac{k_{1} \cdot k_{2}}{k_{1}+k_{2}}
$$

If four teeth are in contact, stiffness can be evaluated:

$$
k=\frac{k_{1} \cdot k_{2}}{k_{1}+k_{2}}+\frac{k_{3} \cdot k_{4}}{k_{3}+k_{4}}
$$

If gear tooth has top-part defect, time is decreasing, while four teeth are in contact. If tooth is cracked, stiffness of this tooth $k_{i}$ is decreasing, meshing stiffness is decreasing too. If there is pitting problem stiffness of tooth $k_{i}$ is decreasing, also a loss of contact is possible. It is very difficult to find the top part defect, because stiffness of tooth is not changing significantly (Fig. 4).

Bearing force is found to be:

$$
F_{b i}=-k_{b} \cdot \tilde{q}_{l}^{1.5}\left(1+a_{b} \cdot\left(1-e_{n}^{2}\right) \frac{\dot{q}_{i}}{\dot{\Delta}}\right)
$$

where $k_{b}$ is bearing contact stiffness, $\dot{\Delta}$ is the penetration rate; $a_{b}$ is the coefficient; $e_{n}$ is the restitution coefficient, $\tilde{q}_{i}$ denotes the excess of displacement in view of the backlash of bearing:

$$
\tilde{q}_{i}=\left\{\begin{array}{l}
q_{i}-\delta_{b}, \text { when } q_{i}>\delta_{b} \\
0, \text { when }-\delta_{b} \leq q_{i} \leq \delta_{b} \\
q_{i}+\delta_{b}, \text { when } q_{i}<-\delta_{b}
\end{array}\right.
$$

where $\delta_{b}$ is backlash in bearing.

Axial displacements of gears are determined as:

$$
\begin{gathered}
m_{1} \cdot \ddot{q}_{1}=\mathrm{F} \cdot \sin \left(\psi_{1}-\alpha_{w 1}\right)+F_{b 1} \\
m_{1} \cdot \ddot{q}_{2}=-\mathrm{F} \cdot \cos \left(\psi_{1}-\alpha_{w 1}\right)+F_{b 2}-m_{1} \cdot g \\
m_{2} \cdot \ddot{q}_{3}=-\mathrm{F} \cdot \sin \left(\psi_{1}-\alpha_{w 1}\right)+F_{b 3} \\
m_{2} \cdot \ddot{q}_{4}=\mathrm{F} \cdot \cos \left(\psi_{1}-\alpha_{w 1}\right)+F_{b 4}-m_{2} \cdot g
\end{gathered}
$$

where $b$ is gravity acceleration, $m_{1}$ is mass of gear, $m_{2}$ is mass of pinion. 
Equation for gear rotation are presented in Skrickij and Bogdevicius [29]. Using the presented model different gear defects can be explored, such as teeth crack, pitting problem and teeth top defect.

\section{Test Rig description and experimental procedure}

This investigation involves experimental testing of spur gear to obtain its dynamic characteristics under different conditions. For this purpose, a series of test were carried out using test rig presented in Fig. 3 , a). One of the engines was operating under motor mode while the other had to carry load. Sensors were placed on the bearing housing in the vertical direction and vibro-acoustic and acoustic emission signals were measured. To measure VS acquisition system MTX 1054, with AS-065 sensor, $100 \mathrm{mV} / \mathrm{g}(1 \ldots 15000 \mathrm{~Hz}, \pm 3 \mathrm{~dB})$ were used, to measure AE signal the data acquisition system Mistras Pocket AE-2, with $R 15 \alpha$ sensor with resonant frequency of $75 \mathrm{kHz}$ was applied. A cylindrical spur gear without lubrication was under investigation. Gear ratio - 1; number of teeth in gears $z=30$ gear module $m=2.5 \mathrm{~mm}$ gear width $b=10 \mathrm{~mm}$. Revolutions are $1487 \mathrm{RPM}$ and constant load.
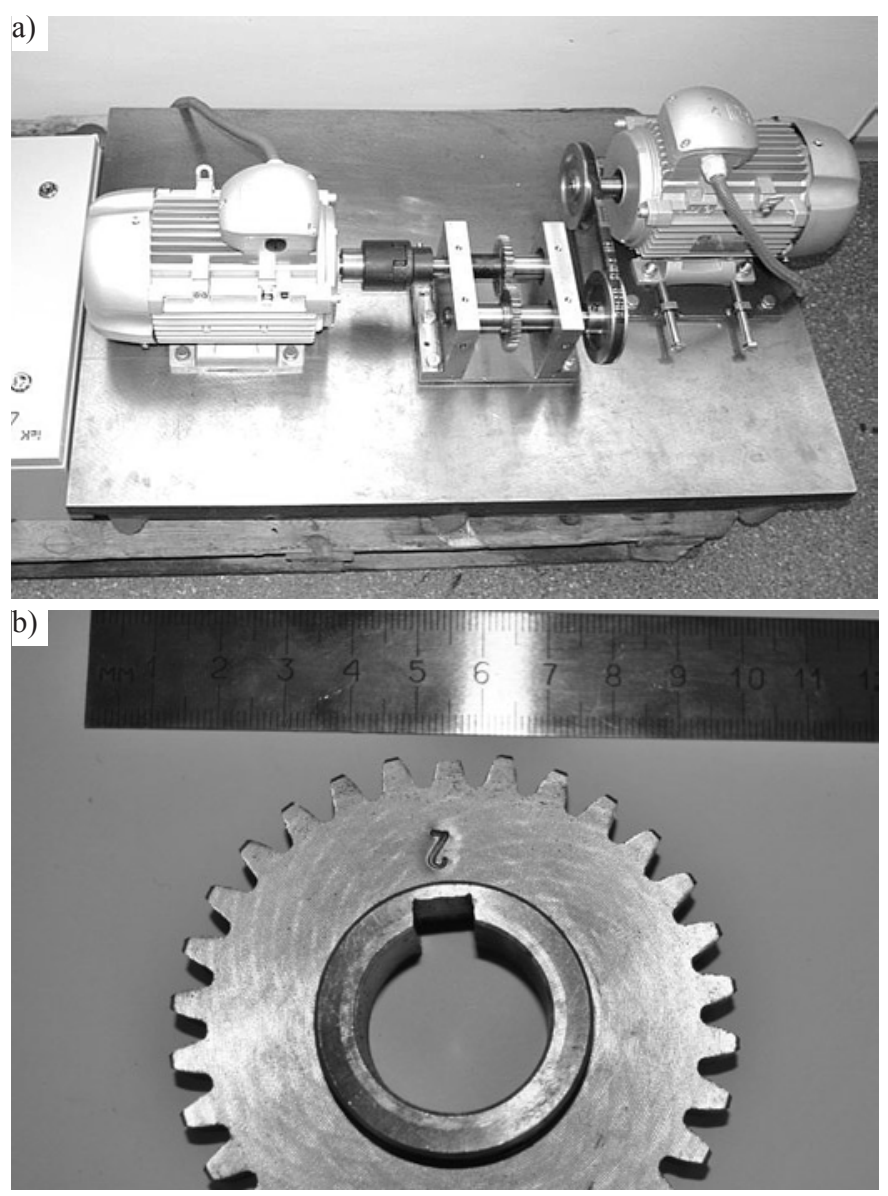

Fig. 3. a) Test rig for spur gear dynamic research; b) gear with a defect

To reduce measuring error, each measurement was repeated five times. The examined cases cover a working gear and the defective gear with 1 and $2 \mathrm{~mm}$ removed from the tooth of the drive gear (Fig 3, b).

\section{Results of mathematical simulation and model veri- fication}

In this part of paper simulation results as well as results of experimental investigation are presented and verification is made.

Modelling, considering three cases, including a working gear, a decrease in the height of the tooth of the gear in $1 \mathrm{~mm}$ and in $2 \mathrm{~mm}$, is proposed. Detection of such defects is a complex problem and occurs only when the upper tooth leaves the mesh Fig.4.

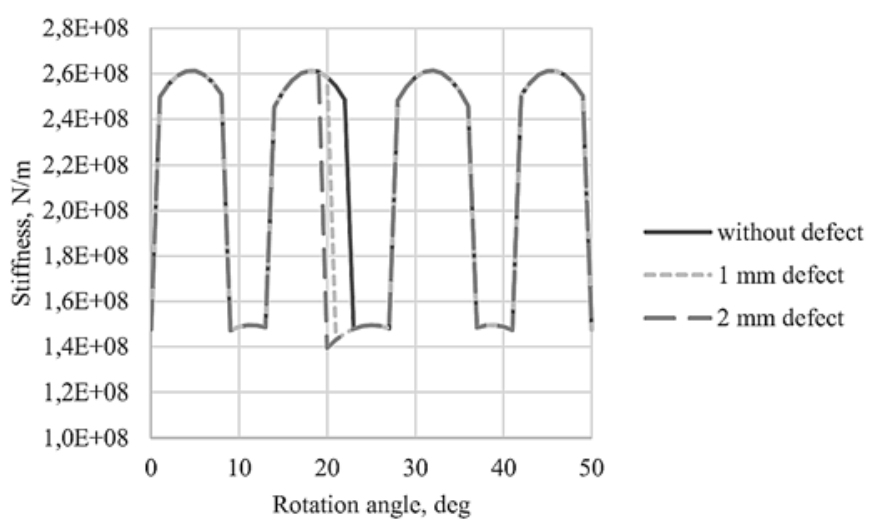

Fig. 4. The influence of a defect on meshing frequency

Discrete Wavelet Transform (DWT) and Daubechies 5 (DB5) Wavelet were selected to conduct mathematical modelling results and experiment. The presented Wavelet has good resolution in the domain of low frequencies. The $\mathrm{AE}$ signal is resolved into 9 intervals from 0 to $50 \mathrm{kHz}$ (Fig. 5, b), the VS is resolved into 6 intervals from 0 to 5 $\mathrm{kHz}$ (Fig. 5, a). For investigation, the following diagnostic parameters were employed: X1 - Peak, X2 - Peak to Peak, X3 - RMS. Usage of these parameters gives good diagnostic results and minimal number of faulty diagnosis [28]. a)

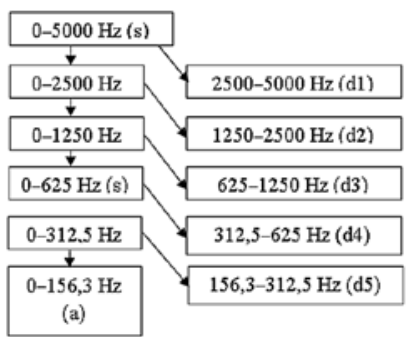

b)

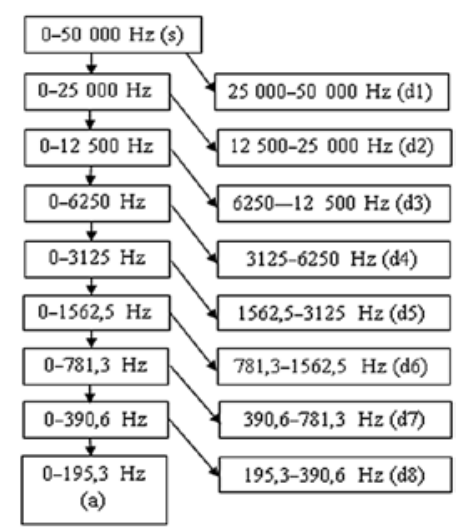

Fig. 5. The decomposition of the signal into frequency intervals: a) the Vibroacoustic signal is resolved into intervals from 0 to $5 \mathrm{kHz}$; b) the Acoustic Emission signal is resolved into 9 intervals from 0 to $50 \mathrm{kHz}$

Using results of the mathematical simulation the values of diagnostic parameters $(\mathrm{X} 1, \mathrm{X} 2, \mathrm{X} 3)$ are calculated in every frequency interval. The examination of the obtained results suggests that mostly the values of diagnostic parameters vary in frequency intervals $\mathrm{d} 1$ $(2500-5000 \mathrm{~Hz})$ and $\mathrm{d} 2(1250-2500 \mathrm{~Hz})$. The X1 parameter has increased by 1.25 times from 2500 to $5000 \mathrm{~Hz}$ (d1) after introducing a defect of $1 \mathrm{~mm}, 1.43$ times after introducing a defect of $2 \mathrm{~mm}$. Same parameter has increased by 1.51 times after introducing a defect of 1 $\mathrm{mm}$ and 1.85 times after introducing a defect of $2 \mathrm{~mm}$ in frequency interval from 1250 to $2500 \mathrm{~Hz}$ (d2) (Fig. 6 a).

The X2 parameter has increased by 1.14 times (Fig. 6 b) from 2500 to $5000 \mathrm{~Hz}(\mathrm{~d} 1)$ after introducing a defect of $1 \mathrm{~mm}, 1.28$ times after introducing a defect of $2 \mathrm{~mm}$. Same parameter has increased by 1.45 times introducing a defect of $1 \mathrm{~mm}$ and 1.80 times after introducing a defect of $2 \mathrm{~mm}$ in frequency interval from 1250 to $2500 \mathrm{~Hz}$ (d2). The increase of X3 parameter (Fig. 7) from 1250 to $5000 \mathrm{~Hz}$ wasn't significant. 


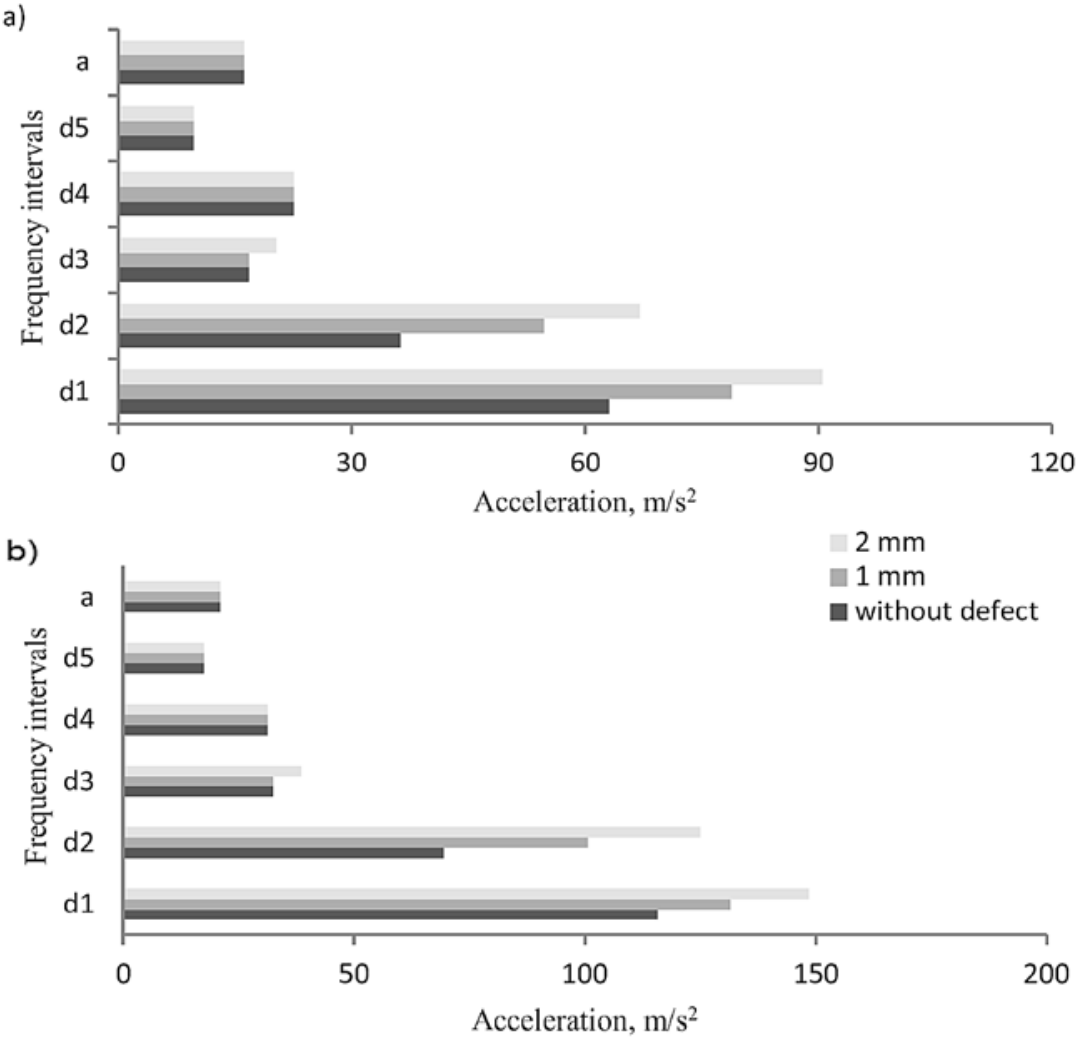

Fig. 6. Results of mathematical modelling, diagnostic parameter: a) X1 (Peak) b) X2 (Peak to Peak)

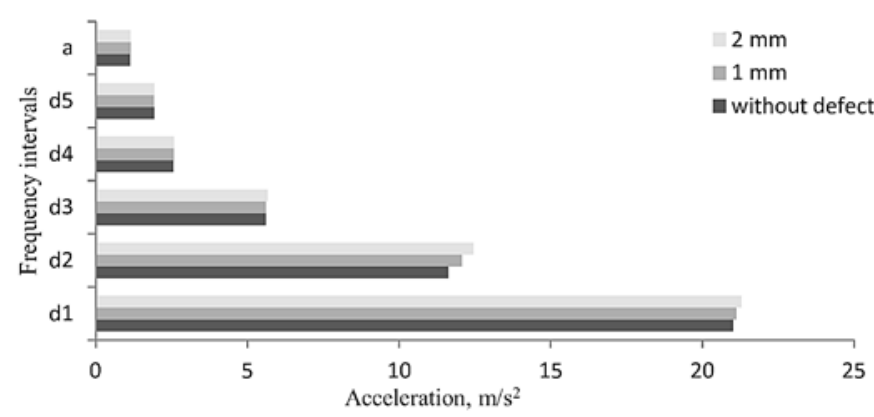

Fig. 7. Results of mathematical modelling, diagnostic parameter X3 (RMS)

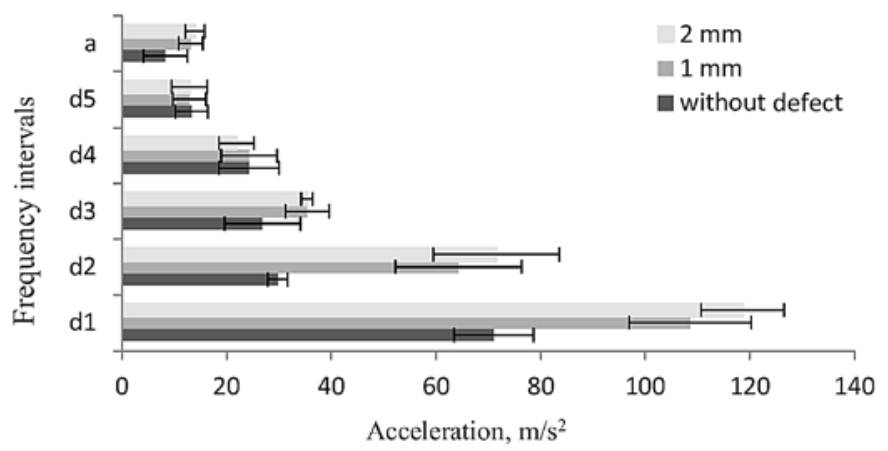

Fig. 8. The Vibro-acoustic signal of the gear, diagnostic parameter X1 (Peak)

Drive vibrations at three different conditions have been measured. The received data was processed by decomposing the signal into frequency intervals. VS signal was divided into 6 intervals (Fig. 5 a), AE signal - into 9 (Fig. 5 b). On the basis of the results of mathematical modelling, two basic diagnostic parameters X1, X2 have been chosen, and also, X3 was checked.
The use of RMS has not been approved. The results and research on mathematical modelling applying the AE method demonstrated a fault of a measuring device, and that 10-bit resolution was not enough.

Defects are best determined under high frequencies. Variations in parameter $\mathrm{X} 1$ are observed within the intervals of $1250-2500 \mathrm{~Hz}$ and $2500-5000 \mathrm{~Hz}$ (Fig. 8). The $\mathrm{X} 1$ parameter has increased by 2.15 times from 1250 to $2500 \mathrm{~Hz}$ (d1) after introducing a defect of $1 \mathrm{~mm}, 2.40$ times after introducing a defect of $2 \mathrm{~mm}$. Same parameter has increased by 1.53 times in frequency interval from 2500 to $5000 \mathrm{~Hz}$ (d2) after introducing a defect of $1 \mathrm{~mm}$ and 1.67 times after introducing a defect of 2 mm (Fig. 8).

The X2 parameter has increased by 2.19 times from 1250 to $2500 \mathrm{~Hz}$ (d1) after introducing a defect of $1 \mathrm{~mm}, 2.38$ times after introducing a defect of $2 \mathrm{~mm}$. Same parameter has increased by 1.56 times from 2500 to $5000 \mathrm{~Hz}$ (d2) after introducing a defect of $1 \mathrm{~mm}$ and 1.71 times after introducing a defect of $2 \mathrm{~mm}$ (Fig. 9).

In parallel with measuring of the VS, AS was assessed. The obtained results are presented below. For interpretation of $\mathrm{AE}$ data in different frequency intervals, the same diagnostic parameters, as in the case of VS, are invoked.

The X1 parameter (Fig. 11) has increased by 1.20 times in d4 $(3125-6250 \mathrm{~Hz})$ frequency range, after introducing a defect of $1 \mathrm{~mm}$, by 1.11 times in $\mathrm{d} 5$ $(1562.5-3125 \mathrm{~Hz})$ frequency range, by 1.08 times in

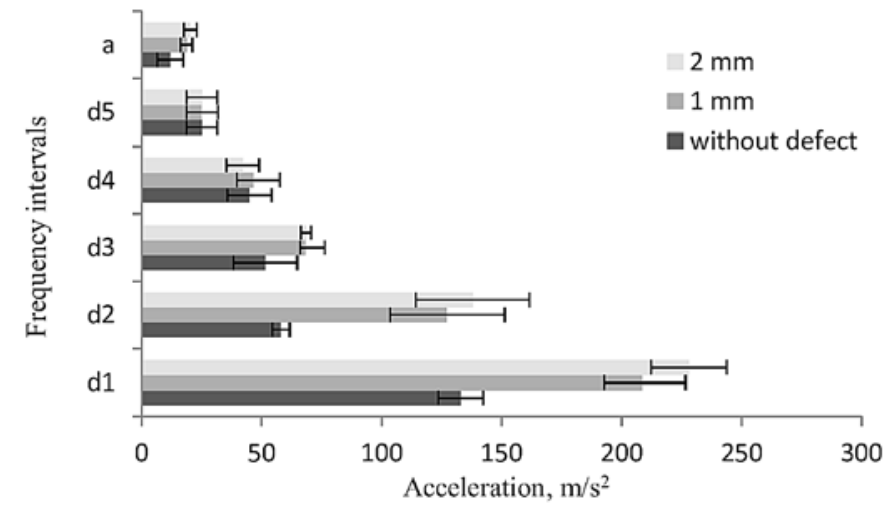

Fig. 9. The Vibro-acoustic signal of the gear, diagnostic parameter X2 (Peak to Peak)

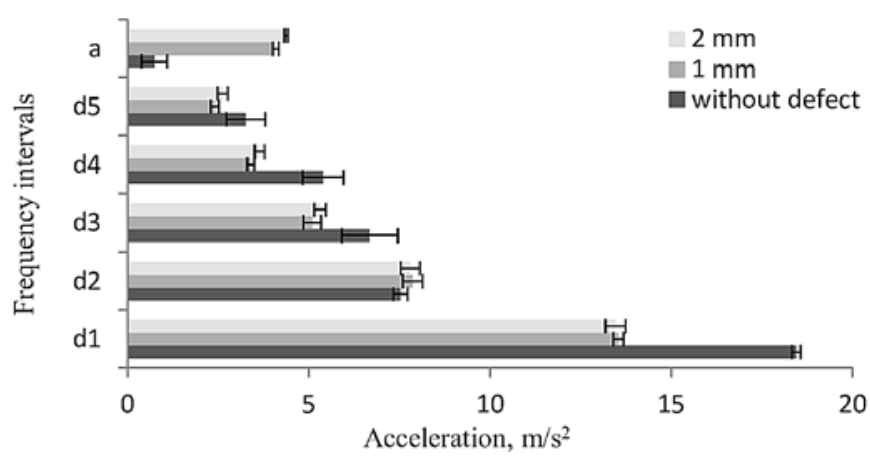

Fig. 10. The Vibro-acoustic signal of the gear, diagnostic parameter X3 (RMS)

d6 (781.3 - $1562.5 \mathrm{~Hz})$ frequency range, by 3.88 times in d2 $(12.5-$ $25 \mathrm{kHz})$ frequency range, by 2.64 times in d $1(25-50 \mathrm{kHz})$ frequency range. After introducing a defect of $2 \mathrm{~mm}, \mathrm{X} 1$ parameter has increased 


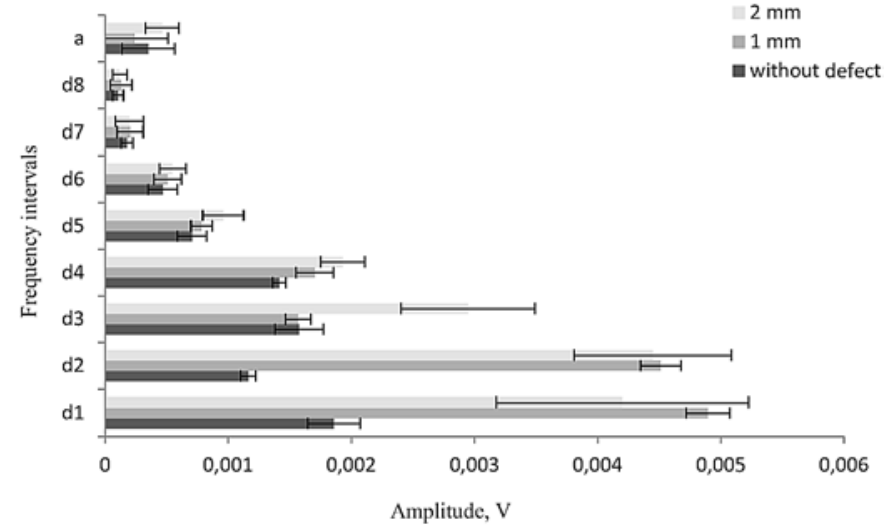

Fig. 11. The acoustic emission signal of the gear, diagnostic parameter X1 (Peak)

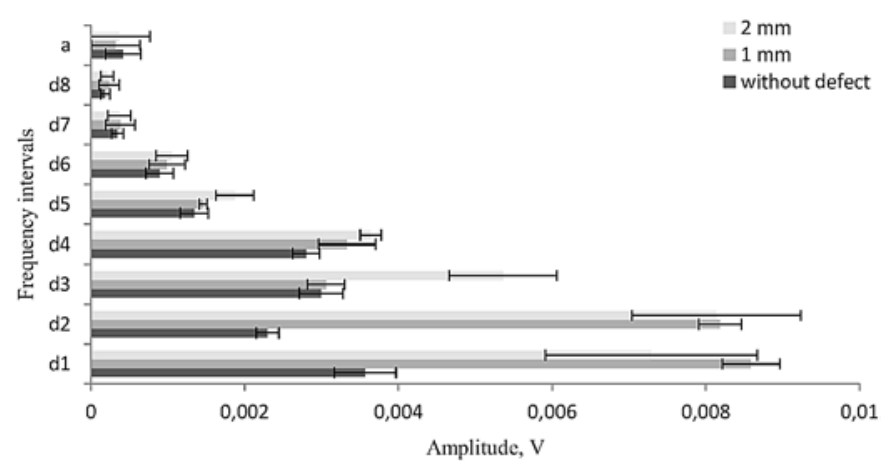

Fig. 12. The acoustic emission signal of the gear, diagnostic parameter X2 (Peak to Peak)

Table 1. Comparison of results

\begin{tabular}{|c|c|c|c|}
\hline \multicolumn{4}{|c|}{$\begin{array}{l}\text { Results using data without wavelet decomposition, } \\
\text { using vibro-acoustic signal }\left(\mathrm{m} / \mathrm{s}^{2}\right)\end{array}$} \\
\hline & $\mathrm{X} 1$ & $\mathrm{X} 2$ & X3 \\
\hline without defect & 105.54 & 182.72 & 22.05 \\
\hline $1 \mathrm{~mm}$ defect & 178.83 & 349.99 & 17.48 \\
\hline diagnostic parameter increase \% & $69 \%$ & $95 \%$ & $21 \%$ decrease \\
\hline $2 \mathrm{~mm}$ defect & 204.38 & 395.98 & 17.60 \\
\hline diagnostic parameter increase $\%$ & $94 \%$ & $117 \%$ & $20 \%$ decrease \\
\hline \multicolumn{4}{|c|}{$\begin{array}{l}\text { Results using proposed method in frequency range } 1250-2500 \mathrm{~Hz} \text {, } \\
\text { using vibro-acoustic signal }\left(\mathrm{m} / \mathrm{s}^{2}\right)\end{array}$} \\
\hline & $\mathrm{X} 1$ & $\mathrm{X} 2$ & $\mathrm{X} 3$ \\
\hline without defect & 29.76 & 57.93 & 7.52 \\
\hline $1 \mathrm{~mm}$ defect & 64.27 & 127.08 & 7.87 \\
\hline diagnostic parameter increase $\%$ & $116 \%$ & $119 \%$ & $5 \%$ \\
\hline $2 \mathrm{~mm}$ defect & 71.52 & 137.91 & 7.79 \\
\hline diagnostic parameter increase \% & $140 \%$ & $138 \%$ & $4 \%$ \\
\hline
\end{tabular}

by 1.36 times in $\mathrm{d} 4$ frequency range, by 1.36 times in $\mathrm{d} 5$ frequency range, by 1.16 times in $\mathrm{d} 6$ frequency range. In $\mathrm{d} 1$ and $\mathrm{d} 2$ parameter $\mathrm{X} 1$ decreased.

The X2 parameter (Fig. 12) has increased by 1.02 times in $\mathrm{d} 3$ $(6250-12500 \mathrm{~Hz})$ frequency range, after introducing a defect of 1 $\mathrm{mm}$, by 1.19 times in d4 $(3125-6250 \mathrm{~Hz})$ frequency range, by 1.09

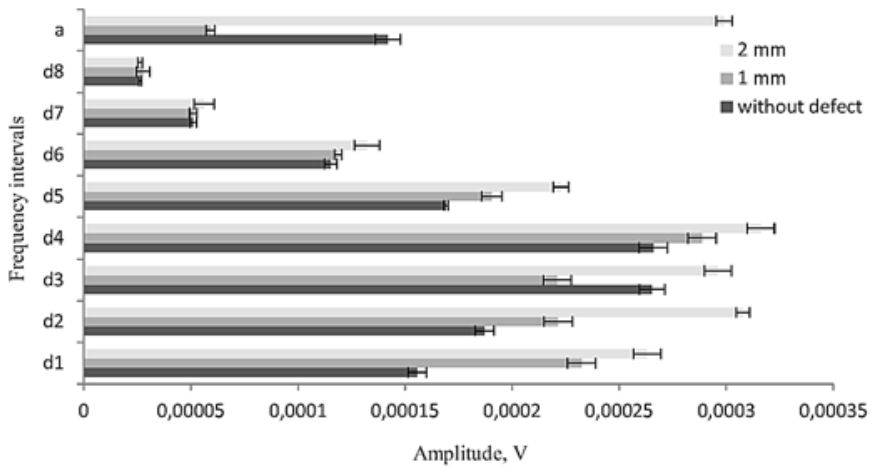

Fig. 13. The acoustic emission signal of the gear, diagnostic parameter X3 (RMS)

times in $\mathrm{d} 5(1562.5-3125 \mathrm{~Hz})$ frequency range, by 1.11 times in $\mathrm{d} 6$ $(781.3-1562.5 \mathrm{~Hz})$ frequency range, by 3.57 times in $\mathrm{d} 2(12.5-25$ $\mathrm{kHz}$ ) frequency range, by 2.41 times in $\mathrm{d} 1(25-50 \mathrm{kHz})$ frequency range. After introducing a defect of $2 \mathrm{~mm}, \mathrm{X} 2$ parameter has increased by 1.79 times in $\mathrm{d} 3$ frequency range, by 1.30 times in $\mathrm{d} 4$ frequency range, by 1.39 times in $\mathrm{d} 5$ frequency range, by 1.18 times in $\mathrm{d} 6$ frequency range. In $\mathrm{d} 1$ and $\mathrm{d} 2$ parameter $\mathrm{X} 2$ decreased.

The X3 parameter (Fig. 13) has increased by 1.09 times in $\mathrm{d} 4$ frequency range, after introducing a defect of $1 \mathrm{~mm}$, by 1.13 times in $\mathrm{d} 5$ frequency range, by 1.03 times in $\mathrm{d} 6$ frequency range, by 1.18 times in $\mathrm{d} 2$ frequency range, by 2.49 times in $\mathrm{d} 1$ frequency range. After introducing a defect of $2 \mathrm{~mm}, \mathrm{X} 3$ parameter has increased by 1.19 times in $\mathrm{d} 5$ frequency range, by 1.32 times in $\mathrm{d} 5$ frequency range, by 1.15 times in $\mathrm{d} 6$ frequency range, by 1.69 times in $\mathrm{d} 1$ frequency range, by 1.64 times in $\mathrm{d} 2$ frequency range.

The analysis of the obtained results using AE indicates that defects are observed in the same frequency intervals as with the VS. However, RMS parameter, on the contrary to the VS, has increased. The parameter has also risen having processed data, and the same results have been received within mathematical modelling. While measuring the VS, 10-bit resolution was not enough, and therefore data has been distorted. Also, the application of the AE method shows that the highest signal gain can be noticed under high frequencies starting from $12500 \mathrm{~Hz}$ and higher. Nevertheless, confidence intervals of parameters $\mathrm{X} 1$ and X2 vary widely in these frequency intervals. The received data do not point to an increase in a defect; however, when the defect occurs, the signal changes considerably, and therefore this parameter can be used for detecting the defect. Same diagnostic parameters but at lower frequencies can be employed for the increase of defect.

Numerical values of diagnostic parameters determined in mathematical modelling and in the run of natural experiments vary. To reach minimum differences, further investigation on transmission measurements are required. Also, backlashes between the gears, in bearings must be established. However, this is not the focus of this paper. For diagnostic purposes, the amount of input data is minimal. Most common defects in the system are introduced, and investigation into the frequency interval where diagnostic parameters change the most is carried out. The proposed model allows assessing the obtained material, and the collected findings only prove that.

The effectiveness of the proposed diagnostic features was checked by comparing the results using data without wavelet decomposition and proposed method, in both cases diagnostic parameters where the same Peak (X1), Peak-to-Peak (X2) and RMS (X3). Using both methods, best results were obtained using Peak and Peak-toPeak parameters, in all the cases proposed method was more sensitive to defect increase, minimal difference was $21 \%$ using X2 parameter 
(gear with $2 \mathrm{~mm}$ defect), maximal $47 \%$ using X1 parameter (gear with $1 \mathrm{~mm}$ defect).

The applicability of the proposed diagnostic features was proved, and proposed method is more sensitive for gear diagnostics with selected defects.

\section{Diagnostic algorithm}

In this part of paper diagnostic algorithm is presented. Firstly, for condition monitoring, the technical parameters of the tested element (initial data) must be established. For testing a gear drive we need to know bearings number, information about the gear module as well as the width and number of teeth and gear ratio.

When the initial data is established, it is entered into a mathematical model and simulation takes place. After that defects are included into the system and simulation runs a few more times. Dynamical characteristics of defective and non-defective gears are compared and frequency intervals indicating the most significant variations in diagnostic parameters are defined (Fig. 14).

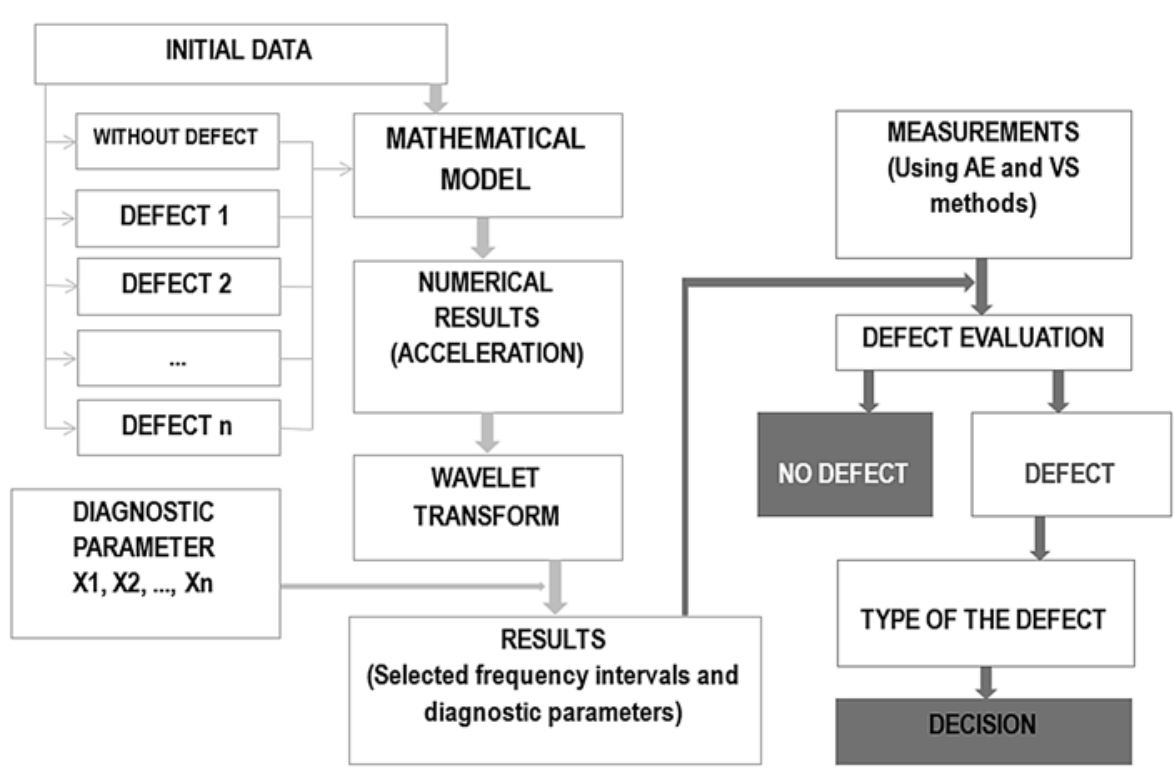

Fig. 14. Results of mathematical modelling, diagnostic parameter: a) X1 (Peak) b) X2 (Peak to Peak) equipment can be performed. If there are no defects in system equipment can be used, if there are defects, type of defects can be found and decision about equipment usage can be carried out.

\section{Conclusions}

1. Algorithm for spur gear condition monitoring has been developed. The algorithm is based on the mathematical model of the spur gear, measurements of Acoustic Emission and the Vibro-acoustic signal as well as on data processing using Wavelet transform.

2. The mathematical model of the spur gear has been presented. The model contains the evaluated backlashes between teeth, time-varying stiffness, variations in the centre distance under the working gear and shaft imbalance. The employment of the presented model assisted in analysing the dynamics of the gear with the removed top-part of the tooth. It was found that diagnostic parameters (X1 - Peak, X2 - Peak to Peak) are most sensitive to the occurrence and expansion of the defect when using the current model.

3. Frequency intervals with the most significant increase in the diagnostic parameter values have been determined. For examining the dynamic parameters of inspected defective gear, frequency interval from $1250 \mathrm{~Hz}$ to $5000 \mathrm{~Hz}$ have been applied. The measurement of the vibration signal and created mathematical model demonstrate that the most sensitive interval is the one between 1250 and $2500 \mathrm{~Hz}$, and an increase in parameter $\mathrm{X} 1$, in this interval, was by $47 \%$ (1 $\mathrm{mm}$ defect) and $46 \%$ (2 $\mathrm{mm}$ defect) larger than that in the same parameter, not referring to the adopted algorithm. The AE method helps to receive good results (no errors in detecting defects are observed) within frequency intervals from 780 to $6250 \mathrm{~Hz}$.

4. Proposed algorithm can be applied on gears with different ratios. There is a possibility that frequency intervals where the most significant increase in the values of diagnostic parameters can be seen, will be different from that proposed in paper, but they can be calculated easily by using mathematical model.

The conducted research has disclosed that diagnostic parameters Peak and Peak to Peak are the best option for spur gear condition monitoring using proposed algorithm. Upon the establishment of frequency intervals most sensitive to detecting failures, testing of the real

\section{References}

1. Amabili M, Rivola A. Dynamic analysis of spur gear pairs: steady-state response and stability of the SDOF model with time-varying meshing damping. Mech. Syst. Signal Process 1997; 11: 375-390, https://doi.org/10.1006/mssp.1996.0072.

2. Cheon G J. Nonlinear behavior. Analysis of spur gear pairs with a one-way clutch. Journal of Sound and Vibration 2007; 301: 760-776, https://doi.org/10.1016/j.jsv.2006.10.040.

3. Fakher C, Walid B, Mohamed S A, Mohamed H. Effect of spalling or tooth breakage on gear mesh stiffness and dynamic response of a one-stage spur gear transmission. European Journal of Mechanics A/Solids 2008; 27: 691-705, https://doi.org/10.1016/j.euromechsol.2007.11.005.

4. Fakhfakh T, Walha L, Louati J, Haddar M. Effect of manufacturing and assembly defects on two-stage gear system vibration. The International Journal of Advanced Manufacturing Technology 2005; 29(9): 1008-1018, https://doi.org/10.1007/s00170-004-2253-x.

5. Frolov V K, Kosarev O I. Control of gear vibrations at their source. International Applied Mechanics 2003; 39(1): 49-55, https://doi. org/10.1023/A:1023612015873.

6. He Q, Kong F, Yan R. Subspace- based gearbox condition monitoring by kernel principal component analysis. Mechanical Systems and Signal Processing 2007; 21: 1755-1772, https://doi.org/10.1016/j.ymssp.2006.07.014.

7. He S, Cho S, Singh R. Prediction of dynamic friction forces in spur gears using alternate sliding friction formulations. Journal of Sound and Vibration 2008; 309: 843-851, https://doi.org/10.1016/j.jsv.2007.06.077. 
8. Jia S X, Howard I. Comparison of localized spalling and crack damage from dynamic modelling of spur gear vibrations. Mechanical Systems and Signal Processing 2006; 20: 332-349, https://doi.org/10.1016/j.ymssp.2005.02.009.

9. Kahraman A, Singh R. Non-linear dynamics of a spur gear pair. Journal of Sound and Vibration 1990; 142(1): 49-75, https://doi. org/10.1016/0022-460X(90)90582-K.

10. Kang Y, Wang C-C, Chang Y-P. Gear fault diagnosis in time domains by using Bayesian networks. Theoretical Advances and Applications of Fuzzy Logic and Soft. Series: Computing Advances in Soft Computing 2007; 42: 741-751, https://doi.org/10.1007/978-3-540-72434-6_75.

11. Kiekbusch T, Howard I. A Common Formula for the Combined Torsional Mesh Stiffness of Spur Gears. Proceedings of the 5th Australasian Congress on Applied Mechanics (ACAM 2007), Brisbane, Australia 2007; 710-716.

12. Kuang J H, Lin A D. The effect of tooth wear on the vibration spectrum of a spur gear pair. Journal of Vibration and Acoustics 2001; 123(3): 311-317, https://doi.org/10.1115/1.1379371.

13. Kuang J H, Yang Y T. An estimate of mesh stiffness and load sharing ratio of a spur gear pair. in Proceeding of ASME 6th International Power Transmission and Gearing Conference, 13-16 September 1992, Scottsdale, Arizona 1992; 1-9.

14. Lei Y, Zuo M J. Gear crack level identification based on weighted K nearest neighbour classification algorithm. Mechanical Systems and Signal Processing 2009; 23(5): 1535-1547, https://doi.org/10.1016/j.ymssp.2009.01.009.

15. Litak G, Friswell M I. Dynamics of a gear system with faults in meshing stiffness. Nonlinear Dynamics 2005; 41: 415-421, https://doi. org/10.1007/s11071-005-1398-y.

16. Loutas T H, Roulias D, Pauly E, Kostopoulos V. The combined use of vibration, acoustic emission and oil debris on-line monitoring towards a more effective condition monitoring of rotating machinery. Mechanical Systems and Signal Processing 2011; 25(4): 1339-1352, https:// doi.org/10.1016/j.ymssp.2010.11.007.

17. Ma H, Pang X, Feng R, Song R, Wen B. Fault features analysis of cracked gear considering the effects of the extended tooth contact. Engineering Failure Analysis 2015; 48: 105-120, https://doi.org/10.1016/j.engfailanal.2014.11.018.

18. Maliha R, Dogruer C U, Özgüven H N. Nonlinear dynamic modeling of gear-shaft-disk-bearing systems using finite elements and describing functions. Journal of Mechanical Design 2004; 126(3): 534-541, https://doi.org/10.1115/1.1711819.

19. Martin H R. Statistical moment analysis as a means of surface damage detection. Proceedings of the 7th International Modal Analysis Conference, Society for Experimental Mechanics, Schenectady, NY 1989; 1016-1021.

20. Mba D. Acoustic Emissions and monitoring bearing health. Tribology Transactions 2003; 46(3): 447-451, https://doi. org/10.1080/10402000308982649.

21. McClintic K, Lebold M, Maynard K, Byington C, Campbell R. Residual and difference feature analysis with transitional gearbox data. Proceedings of the 54th Meeting of the Society for Machinery Failure Prevention technology, Virginia Beach, VA, May 1-4 2000; $635-645$.

22. Mohammeda O D, Rantatalo M, Aidanpää J O, Kumar U. Vibration signal analysis for gear fault diagnosis with various crack progression scenarios. Mechanical Systems and Signal Processing 2013; 41: 176-195, https://doi.org/10.1016/j.ymssp.2013.06.040.

23. Ozguven H N, Houser D R. Mathematical model used in gear dynamics - a review. Journal of Sound and Vibration 1988; 121: 383-411, https://doi.org/10.1016/S0022-460X(88)80365-1.

24. Qu J, Liu Z, Zuo M J, Huang H-Z. Feature selection for damage degree classification of planetary gearboxes using support vector machine. Proceedings of the Institution of Mechanical Engineers, Part C. Journal of Mechanical Engineering Science 2011; 225(9): 2250-2264, https://doi.org/10.1177/0954406211404853.

25. Sait A S, Sharaf-Eldeen Y I. A review of gearbox condition monitoring based on vibration analysis techniques diagnostics and prognostics. Proceedings of the 29th IMAC, A Conference on Structural Dynamics 2011; 307-324, https://doi.org/10.1007/978-1-4419-9428-8_25.

26. Samanta B, Al-Balushi K R. Artificial neural network based fault diagnostics of rolling element bearings using time-domain features. Mechanical Systems and Signal Processing 2003; 17(2): 317-328, https://doi.org/10.1006/mssp.2001.1462.

27. Saxena A, Parey A, Chouksey M. Effect of shaft misalignment and friction force on time varying mesh stiffness of spur gear pair. Engineering Failure Analysis 2015; 49: 79-91, https://doi.org/10.1016/j.engfailanal.2014.12.020.

28. Skrickij V, Bogdevičius M, Junevičius R. Diagnostic features for the condition monitoring of hypoid gear utilizing the wavelet transform, Applied Acoustics 2016; 106: 51-62, https://doi.org/10.1016/j.apacoust.2015.12.018.

29. Skrickij V, Bogdevičius M. Vehicle gearbox dynamics: centre distance influence on mesh stiffness and spur gear dynamics. Transport 2010; 25(3): 278-286, https://doi.org/10.3846/transport.2010.34.

30. Staszewski W J, Worden K. Classification of faults in gearboxes - pre-processing algorithms and neural networks. Neural Computing \& Applications 1997; 5(3): 160-183, https://doi.org/10.1007/BF01413861.

31. Taylor J I, Kirkland D W. The bearing analysis handbook: a practical guide for solving vibration problems in bearings. Vibration Consultant. 2004.

32. Utagawa M. Dynamic loads on spur gear teeth. The Japan Society of Mechanical Engineers 1958; 1(4): 397-403, https://doi.org/10.1299/ jsme1958.1.397.

33. Vaishya M, Singh R. Sliding friction-induced non-linearity and parametric effects in gear dynamics. Journal of sound and vibration 2001; 248(4): 671-694, https://doi.org/10.1006/jsvi.2001.3818.

34. Walha L, Fakhfakh T, Haddar M. Nonlinear dynamics of a two-stage gear system with mesh stiffness fluctuation, bearing flexibility and backlash. Mechanism and Machine Theory 2009; 44(5): 1058-1069, https://doi.org/10.1016/j.mechmachtheory.2008.05.008.

35. Wang J, Li R, Peng X. Survey of nonlinear vibration of gear transmission systems. Applied Mechanics Reviews 2003; 56: 309-329, https:// doi.org/10.1115/1.1555660.

36. Wojnarowski J, Onishchenko V. Tooth wear effects on spur gear dynamics. Mechanism and Machine Theory 2003; 38: 161-178, https://doi. org/10.1016/S0094-114X(02)00091-5.

37. Yang D C H, Lin J Y. Hertzian damping, tooth friction and bending elasticity in gear impact dynamics. Journal of Mechanisms, Transmissions, and Automation in Design 1987: 109(2): 189-96, https://doi.org/10.1115/1.3267437.

38. Yu J-B. Bearing performance degradation assessment using locality preserving projections. Expert Systems with Applications 2011; 38: 7440-7450, https://doi.org/10.1016/j.eswa.2010.12.079.

39. Zakrajsek J J, Townsend D P, Decker H J. An analysis of gear fault detection methods as applied to pitting fatigue failure data, The Systems engineering Approach to Mechanical Failure Prevention, Technical report, 47th Meeting of the MFPG 1993. 
40. Zouari S, Maatar M, Fakhfakh T, Haddar M. Three-dimensional analyses by finite element method of a spur gear: effect of cracks in the teeth foot on the mesh stiffness. Journal of Failure Analysis and Prevention 2007; 7: 475-481, https://doi.org/10.1007/s11668-007-9078-5.

\section{Viktor SKRICKIJ}

Faculty of Transport Engineering

Vilnius Gediminas Technical University

Plytines str., 27-307 Vilnius, Lithuania

\section{Marijonas BOGDEVIČIUS}

Faculty of Transport Engineering

Vilnius Gediminas Technical University

Plytines str., 27-315 Vilnius, Lithuania

\section{Rasa ŽYGIENĖ}

Faculty of Transport Engineering

Vilnius Gediminas Technical University

Plytines str., 27-304 Vilnius, Lithuania

E-mails: viktor.skrickij@vgtu.It, marijonas.bogdevicius@vgtu.It, rasa.zygiene@vgtu.lt 